\title{
Controlling Enzymatic Polymerization from Surfaces with Switchable Bioaffinity
}

\author{
Mohammad Divandari ${ }^{a,{ }^{\dagger}}$, Jonas Pollard ${ }^{b, \dagger}$, Ella Dehghani, ${ }^{a}$ \\ Nico Bruns ${ }^{b, \S}, *$, Edmondo M. Benetti ${ }^{a, \S}, *$
}

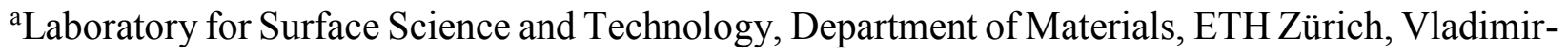
Prelog-Weg 5, CH-8093 Zürich, Switzerland

${ }^{\mathrm{b}}$ Adolphe Merkle Institute, Chemin des Verdiers 4, CH-1700 Fribourg, Switzerland

$\dagger$ These authors contributed equally

$\S$ These authors contributed equally

* Corresponding authors' email addresses: nico.bruns@unifr.ch, edmondo.benetti@mat.ethz.ch

KEYWORDS: polymer brushes; biocatalytic ATRP; controlled polymerizations; thin films; surface modification. 


\section{ABSTRACT}

The affinity of surfaces towards proteins is found to be a key parameter to govern the synthesis of polymer brushes by surface-initiated biocatalytic atom transfer radical polymerization (SIbioATRP). While the "ATRPase" hemoglobin $(\mathrm{Hb})$ stimulates only a relatively slow growth of protein repellent brushes, the synthesis of thermoresponsive grafts can be regulated by switching the polymer's attraction towards proteins across its lower critical solution temperature (LCST). Poly( $N$-isopropyl acrylamide) (PNIPAM) brushes are synthesized in discrete steps of thickness at temperatures above LCST, while the biocatalyst layer is refreshed at T $<$ LCST. Multistep surfaceinitiated biocatalytic ATRP demonstrates a high degree of control, results in high chain end group fidelity and enables the synthesis of multiblock-copolymer brushes under fully aqueous conditions. The activity of $\mathrm{Hb}$ can be further modulated by the accessibility of the heme pocket within the protein. The multistep polymerization is accelerated at acid $\mathrm{pH}$, where the enzyme undergoes a transition from its native to a molten globule conformation. The controlled synthesis of polymer brushes by multistep SI-bioATRP highlights how a biocatalytic synthesis of grafted polymer films can be precisely controlled through the modulation of the polymer's interfacial physicochemical properties, in particular of the surface's affinity toward proteins. This is not only of importance to gain a predictive understanding of surface-confined enzymatic polymerizations but also represents a new way to translate bioadhesion into a controlled functionalization of materials. 


\section{Introduction}

Materials scientists have developed a multitude of robust protocols to modify and functionalize surfaces with the aim to tune precisely the chemical, physical, and biological properties of synthetic biointerfaces, ${ }^{1,2}$ such as scaffolds for tissue engineering, ${ }^{3}$ cell-sensitive platforms, ${ }^{4-6}$ antifouling surfaces, ${ }^{7}$ and biosensors. ${ }^{8}$ The general fabrication strategy for obtaining biologically active materials relies on the modification of a synthetic surface through chemical reactions or physical treatments, with the aim of inducing, and preferentially controlling, a certain biological process within the surrounding environment. In this study, we follow an opposite strategy, demonstrating how the fine control over the affinity of a surface towards a catalytically active biomolecule can be exploited to fabricate polymer films with molecular and structural precision. In particular, we exploit the polymerization activity of enzymes and tune the adhesion of proteins on surfaces in order to trigger and modulate the growth of synthetic macromolecules, so-called polymer brushes. ${ }^{9}$

Surface-initiated reversible-deactivation radical polymerizations (also termed controlled radical polymerizations) are a common way to synthesize polymer brushes ${ }^{10-12}$ and include methods such as atom transfer radical polymerization (ATRP), ${ }^{13}$ nitroxide-mediated polymerization (NMP) ${ }^{14}$ and reversible addition-fragmentation chain-transfer (RAFT) polymerization. ${ }^{15}$ While these processes produce well-defined polymer brushes, they often require reaction conditions, catalysts, or reagents that can be harmful and that are not compatible with biological systems. An alternative strategy is to use biological catalysts such as enzymes to initiate and control surface-confined polymerization. ${ }^{16-18}$ Examples are the enzymatic synthesis of polyhydroxyalkanoates on surfaces, ${ }^{19,20}$ lipase-catalyzed ring-opening polymerizations of $\varepsilon$-caprolactone, ${ }^{21,22}$ as well as peroxidase-mediated radical polymerization of aniline ${ }^{23-26}$ and acrylamide. ${ }^{27,28}$ Moreover, surface- 
initiated enzymatic polymerizations of DNA by terminal deoxynucleotidyl transferase have been explored to amplify signals in biosensing. ${ }^{29-34}$ Recently, we and others have shown that metalloproteins such as hemoglobin $(\mathrm{Hb})$, horseradish peroxidase, and laccase can catalyze ATRP in solution ${ }^{35-42}$ and on surfaces. ${ }^{39,43,44}$ These biocatalysts represent a biocompatible, nontoxic and environmentally friendly alternative to conventional, transition metal-based ATRP catalysts. Irrespective of the actual type of polymerization, a prerequisite for an effective biocatalytic synthesis of polymer brushes is that the enzyme must get in close contact with the surface to initiate and/or catalyze the growth of polymer chains.

Here, we demonstrate how the fine control over the interaction between proteins and surfaces can be used to modulate the enzymatic synthesis of polymer brushes by surface-initiated biocatalytic ATRP (SI-bioATRP). The affinity of the surface toward proteins was tuned by polymerizing two different monomers, $N$-isopropyl acrylamide (NIPAM) and poly(ethylene glycol) acrylate (PEGA). PNIPAM brushes undergo a reversible transition from a hydrated and protein-repelling state at room temperature to a collapsed and protein-adhesive conformation above its lower critical solution temperature (LCST), centered around $30-34{ }^{\circ} \mathrm{C} .{ }^{45-47}$ In contrast, poly[poly(ethylene glycol) acrylate] (PPEGA) grafts are protein repellent independent of the temperature. ${ }^{48}$ SIbioATRP of both monomers results in homogeneous films that could be reinitiated several times. The growth of PNIPAM at $37^{\circ} \mathrm{C}$ is much more pronounced than the thickness increase of the same polymer at $25{ }^{\circ} \mathrm{C}$ or of PPEGA at both temperatures. The interaction between the catalyst and growing PNIPAM has to be reversibly triggered to allow for catalyst regeneration at the brushmedium interface and to enable the diffusion of monomer to the propagating sites (Scheme 1). Because the affinity of the surface toward the catalyst can be precisely controlled by switching the physical properties of the growing PNIPAM grafts in response to a relatively narrow temperature 
variation, high molar mass brushes can be successfully synthesized through multiple reinitiation (at $T>\mathrm{LCST}$ ) and rinsing (at $T<\mathrm{LCST}$ ) steps, reaching $\sim 30 \mathrm{~nm}$ of dry thickness in a fully controlled process, i.e., following linear film-thickening rates. ${ }^{49}$ This is a highly relevant result, considering that in aqueous media the synthesis of brushes by conventional SI-ATRP suffers from an intrinsic loss of control due to radical termination reactions and catalyst decomposition. ${ }^{50-52}$ Polymerization studies are complemented by an in-depth characterization of the biocatalyst before and during the polymerization reactions. A partially unfolded conformation of $\mathrm{Hb}$ under acidic conditions favors the accessibility of the catalytic site to the polymer chains, confirming that the reciprocal interaction between the growing polymer surface and the catalyst plays a key role in regulating SI-bioATRP.

\section{Materials and Methods}

Dopamine hydrochloride (Sigma-Aldrich), sodium nitrate (Sigma-Aldrich), sulfuric acid (SigmaAldrich), (+)-sodium L-ascorbate (NaAsc; Sigma-Aldrich), $n$-hexane (Sigma-Aldrich), dichloromethane $99.8 \%$ extra dry (DCM; Acros organics), 2-bromoisobutyryl bromide (SigmaAldrich), and triethylamine (Sigma-Aldrich) were used as received. Hemoglobin (Hb) from bovine blood (lyophilized powder; Sigma-Aldrich) and $\mathrm{N}$-(2-hydroxyethyl)maleimide (HEMI; SigmaAldrich) were used to prepare Cys-blocked-Hb (see following section). NIPAM (Sigma-Aldrich) was re-crystallized from $n$-hexane. Poly(ethylene glycol) methyl ether acrylate $\left(\mathrm{M}_{\mathrm{n}}=480 \mathrm{~g} \mathrm{~mol}^{-1}\right.$; PEGA; Sigma-Aldrich) was passed through a basic alumina column to remove the inhibitor. Ultrapure water $(18.2 \mathrm{M} \Omega \mathrm{cm})$ was obtained from Milli-Q Ultrapure water purification systems. Acetic acid (Sigma-Aldrich) sodium acetate tri-hydrate (Sigma-Aldrich), monobasic sodium phosphate (Sigma-Aldrich) and sodium hydroxide (Sigma-Aldrich) were used for the preparation of the 
buffer solutions. Briefly, 0.1 M stock solutions of acetic acid and sodium acetate tri-hydrate were mixed in the following volumetric ratios $(0.1 \mathrm{M}$ acetic acid : $0.1 \mathrm{M}$ sodium acetate $), \mathrm{pH} 3=98.23$ : $1.77, \mathrm{pH} 4=84.70: 15.30, \mathrm{pH} 5=35.70: 64.30$. The $0.1 \mathrm{M}$ phosphate buffer $\mathrm{pH} 6$ and 6.5 were prepared in a $1 \mathrm{~L}$ volumetric flask containing $500 \mathrm{~mL}$ of $0.2 \mathrm{M}$ monobasic sodium phosphate. The $\mathrm{pH}$ was adjusted by addition of sodium hydroxide to the respective $\mathrm{pH}$ and the volumetric flask was filled up to $1 \mathrm{~L}$ with ultra-pure water.

\section{Synthesis of Cysteine-blocked Hemoglobin}

The presence of surface-exposed cysteines in hemoglobin can lead to chain-transfer during radical polymerization. ${ }^{36}$ To avoid that, the cysteine groups of the protein were modified with a maleimide reagent. The procedure was adapted from the one previously reported by Silva et al. ${ }^{36} \mathrm{Hb}(1000$ $\mathrm{mg}, 0.0155 \mathrm{mmol})$ and HEMI $(65.6 \mathrm{mg}, 0.465 \mathrm{mmol})$ were incubated in $300 \mathrm{~mL}$ of $0.1 \mathrm{M}$ sodium phosphate buffer $(\mathrm{pH} 6.5,150 \mathrm{mM} \mathrm{NaCl})$ for $2 \mathrm{~h}$ at $37^{\circ} \mathrm{C}$. The modified protein was then concentrated using a JumboSep 10k starter kit (molecular weight cut-off (MWCO) $10000 \mathrm{~g} \mathrm{~mol}^{-}$

1; Pall Life Sciences). The cysteine-blocked $\mathrm{Hb}$ was then desalted twice against $0.1 \mathrm{M}$ sodium phosphate buffer $(\mathrm{pH} 6.0,150 \mathrm{mM} \mathrm{NaCl})$ and three times against ultra-pure water using the same centrifugal device. The concentrated solution was then centrifuged at $4700 \mathrm{G}$ for 15 minutes to remove any denatured protein. Before polymerizations, $\mathrm{Hb}$ was mixed with $0.1 \mathrm{M}$ acetate buffer at $\mathrm{pH} 4$ and concentrated three times in Macrosep Advance Centrigual Device 10K MWCO (Pall Life Sciences). The absorbance of the stock solution of $\mathrm{Hb}$ was finally measured at $406 \mathrm{~nm}$ by $\mathrm{UV}$-Vis spectroscopy $\left(\varepsilon=357747 \mathrm{M}^{-1} \mathrm{~cm}^{-1}\right.$ per $\mathrm{Hb}$; determined experimentally by a dilution series of commercial metHb) to calculate the concentration of $\mathrm{Hb}$ following the Beer-Lambert law. 


\section{Synthesis of Nitrodopamine.}

Dopamine hydrochloride $(2.0 \mathrm{~g}, 10.5 \mathrm{mmol})$ and sodium nitrite $(1.6 \mathrm{~g}, 23.2 \mathrm{mmol})$ were dissolved in water $(40 \mathrm{~mL})$ and cooled down to $0^{\circ} \mathrm{C}$. Sulfuric acid $(18.7 \mathrm{mmol}$ in $15 \mathrm{~mL}$ water) was added slowly to the mixture during which a yellow precipitate formed. After stirring at room temperature overnight the precipitate was filtered and re-crystallized from water. The product was finally dried under high vacuum to give nitrodopamine (ND) as the 6-nitro-3-hydroxytyramine hemi-sulfate salt. $^{53}$

\section{Surface functionalization}

Silicon wafers $(\mathrm{P} / \mathrm{B}<100>$, Si-Mat Silicon Wafers, Germany) were coated by reactive magnetron sputtering (PSI Villigen, Switzerland, high purity Ti targets) with $20 \mathrm{~nm}$ of titanium oxide $\left(\mathrm{TiO}_{2}\right)$. The obtained $\mathrm{TiO}_{2}$-coated substrates were subsequently cut into $1 \times 1 \mathrm{~cm}$ wafers and sonicated twice for $10 \mathrm{~min}$ in toluene and twice for $10 \mathrm{~min}$ in isopropanol. Finally, they were subjected to 40 min of UV/Ozone cleaning (UV clean model 135500, Boekel scientific, PA, USA). $\mathrm{TiO}_{2}$-coated quartz crystal microbalance with dissipation (QCM-D) sensors (QSX 310 Ti, Q-Sense, Gothenburg, Sweden) were cleaned in the same way.

$\mathrm{TiO}_{2}$-coated substrates and QCM-D sensors were subsequently incubated overnight in a $0.1 \mathrm{mg}$ $\mathrm{ml}^{-1}$ solution of ND in ultra-pure water followed by rinsing with ethanol and ultra-pure water. They were finally dried under a stream of nitrogen. The ND-functionalized surfaces were then incubated in a solution of $20 \mathrm{ml}$ dry DCM, $0.2 \mathrm{ml}$ of 2-bromoisobutyryl bromide and $0.2 \mathrm{ml}$ triethylamine to form the ATRP initiator layer on the surfaces. Finally, the functionalized substrates and QCM-D sensors were washed thoroughly with DCM and dried under a stream of nitrogen. 


\section{SI-bioATRP}

In a typical polymerization, the monomer (NIPAM or PEGA) (1.817 mmol), NaAsc (5.40 mg, $27.2 \mu \mathrm{mol}), \mathrm{Hb}(5.9 \mathrm{mg}, 91 \mathrm{nmol})$ and $3.2 \mathrm{ml}$ of $0.1 \mathrm{M}$ acetate buffer (pH 3, 4 or 5) were mixed and deoxygenated by nitrogen bubbling for 30 minutes. Subsequently, the solution was transferred via a syringe to a flask containing the initiator-functionalized substrates kept under nitrogen. The reaction was carried out for the required time at a set temperature using a temperature controlled water bath. After SI-bioATRP, the substrates were washed extensively with ultra-pure water and dried under a stream of nitrogen.

In the case of multiple re-initiation experiments, the polymerization time was set to one hour, after which the substrates were removed from the polymerization solution and washed extensively with ultrapure-water at room temperature (RT) and dried under a stream of nitrogen. Subsequently, the dry thickness of the formed film on the substrates was measured by VASE and they were reincubated in a fresh polymerization solution and polymerized for another hour. This cycle was repeated several times.

\section{Chain extension of PPEGA brushes by conventional ATRP}

In brief, $10 \mathrm{ml}(22.7 \mathrm{mmol})$ of PEGA was dissolved into a water/methanol mixture $($ PEGA:water:methanol = 10:6:1.5 v/v). To this solution, $53 \mathrm{mg}(339.7 \mu \mathrm{mol})$ of 2,2' bipyridine was added and the mixture was deoxygenated by nitrogen bubbling for $30 \mathrm{~min}$. Later on, the solution was transferred via a cannula into a flask containing $8 \mathrm{mg}(80.8 \mu \mathrm{mol})$ of $\mathrm{CuCl}$ and $3 \mathrm{mg}$ $(22.3 \mu \mathrm{mol})$ of $\mathrm{CuCl}_{2}$. The mixture was stirred until a homogenous solution formed. Finally, the polymerization mixture was transferred to a flask containing PPEGA-coated substrates, previously synthesized by SI-bioATRP at $25^{\circ} \mathrm{C}, \mathrm{pH} 4$ for 6 hours. PEGA polymerization was carried out at $60{ }^{\circ} \mathrm{C}$ for $1 \mathrm{~h}$. After this reaction time, the polymerization was terminated by exposing the flask to 
air, and the substrates were subsequently rinsed extensively with ultra-pure water and finally dried under a stream of nitrogen.

\section{Instrumentation}

The dry thickness of the initiator layer and the PNIPAM and PPEGA brushes was measured with VASE (M-2000F, LOT Oriel GmbH, Germany) in air. At least 3 points on each sample were measured providing average values of thickness and standard deviations. The determination of $\Psi$ (amplitude) and $\Delta$ (phase) as a function of wavelength $(350-800 \mathrm{~nm})$ was carried out by employing the WVASE32 software package (LOT Oriel $\mathrm{GmbH}$ ), using bulk dielectric functions for $\mathrm{Si}, \mathrm{SiO}_{2}$, and $\mathrm{TiO}_{2}$. The brush-supporting substrates were in all cases considered to consist of $\mathrm{Si}$ with a 2 $\mathrm{nm}$ thick $\mathrm{SiO}_{2}$ layer and a $20 \mathrm{~nm}$ thick $\mathrm{TiO}_{2}$ layer. The analysis of the thickness of the brush layers was performed on the basis of a Cauchy model $n=A+B \cdot \lambda^{-2}$; where $n$ is the refractive index, $\lambda$ is the wavelength, $\mathrm{A}=1.45$ and $\mathrm{B}=0.01 .{ }^{54}$

Fourier-transform infrared spectroscopy (FTIR) was used to monitor the chemical composition of the synthesized brush films. FTIR spectra were recorded under vacuum using an infrared spectrometer (IFS 66 V, Bruker Optik GmbH, Germany) equipped with a liquid-nitrogen-cooled MCT detector, applying a transmission mode, while a background spectrum was collected from a freshly cleaned, bare substrate.

X-ray photoelectron spectroscopy (XPS) was employed to perform the elemental analysis of the initiator layers and the polymer brush-coated substrates using a Theta-Probe X-ray photoelectron spectrometer (Thermo Fisher Scientific, USA), equipped with a monochromatic Al Ka source and a beam diameter of $400 \mu \mathrm{m}$. The pass energy was $100 \mathrm{eV}$ for the high-resolution elemental spectra of carbon, oxygen and nitrogen, whereas the pass energy for collecting the survey spectrum was 
$200 \mathrm{eV}$. In order to compensate for the charging of the modified surfaces, an electron-argon-ion flood gun was used. Depth-dependent elemental analysis of the brush-functionalized surfaces was carried out by angle-resolved X-ray photoelectron spectroscopy (ARXPS) using the same instrumentation as introduced above. ARXPS allowed the simultaneous acquisition of spectra at different emission angles, hence alternatively sampling the interfacial and the bulk elemental composition of the brush films. In particular, three measurements were performed for each sample at 8 different emission angles to the surface, ranging from $24.9-81.1^{\circ}$. XPS data analysis was performed using the CasaXPS software.

Static water contact angles (CA) were measured with a Ramé-Hart goniometer (Model 100, RaméHart Instrument Co., USA). The average and standard deviation of the CA were obtained by measuring at least 3 different points on each sample.

Atomic force microscopy (AFM) height micrographs of the brush films were recorded using a Bruker Icon Dimension (Bruker, USA) in tapping mode, and using OMCL-AC160TS-C3 (Olympus, Japan) AFM cantilevers with a spring constant of $26 \mathrm{~N} \mathrm{~m}^{-1}$. The swollen thickness of PNIPAM brushes was measured by mechanically removing the films using plastic tweezers and subsequently measuring the step-height between swollen brushes and the underlying, bare substrate.

Quartz crystal microbalance with dissipation monitoring (QCM-D) (E4 instrument, Q-Sense AB, Sweden) was employed for monitoring in situ the growth of the polymer brushes and the interaction of $\mathrm{Hb}$ with the polymer surfaces. Data analysis was performed with the Q-Soft 301 software (Q-Sense AB). Following the deposition of ATRP initiator monolayers, the sensors were mounted inside the QCM-D apparatus, which was equipped with liquid flow cells (volume $=140$ $\mu 1)$ and a temperature control system. The experiments were performed under stagnant conditions, 
i.e. excess of the fluid was injected until all tubes and the chamber were purged. Then, the flow was stopped and the mixture was left to react or to equilibrate. First, deoxygenated ultra-pure water was injected into the chambers containing the initiator-functionalized sensors. After a steady baseline was recorded at the experimental temperature $\left(25^{\circ} \mathrm{C}\right.$ or $\left.37{ }^{\circ} \mathrm{C}\right)$, the deoxygenated polymerization mixture (NIPAM or PEGA $(1.817 \mathrm{mmol}), \mathrm{NaAsc}(27.2 \mu \mathrm{mol}), \mathrm{Hb}(91 \mathrm{nmol})$ in $0.1 \mathrm{M}$ acetate buffer (3.2 ml, $\mathrm{pH} 4)$ ) was injected into the chamber by an external syringe, while the temperature of the cell was maintained via the temperature controller. After the required polymerization time, the reaction was terminated by injecting non-deoxygenated ultra-pure water. Then, the temperature of the cell at $37{ }^{\circ} \mathrm{C}$ was reduced to $25{ }^{\circ} \mathrm{C}$ and washed with ultra-pure to remove the remaining adsorbed protein and the temperature was increased back to $37^{\circ} \mathrm{C}$. In order to evaluate $\mathrm{Hb}$ adsorption by QCM-D, a solution of $\mathrm{Hb}$ in $\mathrm{pH} 4$ acetate buffer (kept at $\mathrm{RT}$ or $37^{\circ} \mathrm{C}$ prior to injection in to the chamber), with the same enzyme concentration to the one applied for the polymerization reactions $\left(1.84 \mathrm{mg} \mathrm{mL}^{-1}\right)$ was injected in to the chamber. After 1 hour of incubation, the QCM-D sensors were rinsed by injecting ultra-pure water (kept at RT or $37^{\circ} \mathrm{C}$ prior to injection in to the chamber) to wash off any loosely bound enzyme. In order to obtain the hydrated mass adsorbed on the sensors, the frequency $(\Delta f)$ and dissipation shifts $(\Delta D)$ of three different overtones were fitted with an extended viscoelastic model..$^{55}$

For the multiple re-initiation experiments, the polymerization time was set to one hour, after which deoxygenated ultra-pure water (kept at RT prior to injection in to the chamber) was injected to rinse away hemoglobin and reagents and therefore terminate the reaction. After a steady baseline was achieved, a freshly prepared polymerization solution (kept at RT or $37^{\circ} \mathrm{C}$ prior to injection in to the chamber) was injected into the cells to reinitiated SI-bioATRP. The polymerization was carried out for $1 \mathrm{~h}$. The same cycle of reversible termination and re-initiation was repeated 4 times. 
UV-Vis measurements were carried out on a Specord 50 Plus spectrophotometer (Analytik Jena, Germany). The experiments were carried out under aerobic conditions in order to facilitate sample handling. In a typical experiment, stocks solutions of the monomer and NaAsc were prepared by dissolving NIPAM (458.3 mg, $4.05 \mathrm{mmol})$ and NaAsc $(12.1 \mathrm{mg}, 61.1 \mu \mathrm{mol})$ in $5 \mathrm{~mL}$ of $\mathrm{pH} 3, \mathrm{pH}$ 4 or $\mathrm{pH} 5$ sodium acetate buffer $(0.1 \mathrm{M})$. For each experimental condition, $0.7 \mathrm{~mL}$ of this solution was added to $0.2 \mathrm{~mL}$ of the acetate buffer of the respective $\mathrm{pH}$. Finally, $0.1 \mathrm{~mL}$ stock solution of $\mathrm{Hb}\left(18.4 \mathrm{mg} \mathrm{mL}^{-1}, 0.28 \mathrm{mM}\right)$ was added as the last component in order to minimize the time between the addition of the $\mathrm{Hb}$ and the start of the measurement. The final concentration of reagents was $567.8 \mathrm{mM}$ NIPAM and $8.5 \mathrm{mM} \mathrm{NaAsc}$. To record spectra, $0.1 \mathrm{~mL}$ of the reaction mixture was diluted in $0.9 \mathrm{~mL}$ of acetate buffer of the respective $\mathrm{pH}$. Spectral scans were carried out over wavelength ranging from 300 to $800 \mathrm{~nm}$ with a speed of $2 \mathrm{~nm} \mathrm{~s}^{-1}$ at $25{ }^{\circ} \mathrm{C}$ or $37^{\circ} \mathrm{C}$. Reference spectra were taken prior to each measurement with cuvettes filled with acetate buffer of the respective $\mathrm{pH}$.

Circular dichroism (CD) spectra were measured on a J-715 spectropolarimeter (Jasco, USA). As sodium acetate has a UV-cutoff of $205 \mathrm{~nm}$, the buffer concentration was reduced to $0.05 \mathrm{M}$ and the $\mathrm{pH}$ was adjusted with addition of $\mathrm{NaOH}$ and $\mathrm{HCl}$ to $\mathrm{pH} 2.5$ or $\mathrm{pH} 5$. The reagents also absorb in this region. Therefore, $\mathrm{Hb}$ was measured without any additional reagents in the buffer using quartz cuvette with a $2 \mathrm{~mm}$ light path. Hb concentration was adjusted so that HT (voltage) was kept between $200 \mathrm{~V}$ and $700 \mathrm{~V}$. The spectra were recorded at $25^{\circ} \mathrm{C}$ from $200 \mathrm{~nm}$ to $250 \mathrm{~nm}$ with a scanning speed of $10 \mathrm{~nm} \mathrm{~min}{ }^{-1}$, a data pitch of $1 \mathrm{~nm}$ and a bandwidth of $2 \mathrm{~nm}$. The spectra were smoothed over 5 data points. UV-Vis spectra were recorded prior and after CD measurement to ensure that the conformation was the same as observed for these $\mathrm{pH}$ under polymerization conditions. 


\section{Results and Discussion}

\section{SI-bioATRP of NIPAM and PEGA}

BioATRP uses metal-containing enzymes such as $\mathrm{Hb}$ instead of the transition metal complexes that are conventionally used to catalyze ATRP. Hb is composed of two $\alpha$ - and two $\beta$-subunits, with each protein subunit hosting a heme group, i.e., an iron protoporphyrin IX, in a binding pocket. ${ }^{56}$ $\mathrm{Hb}$ is a promiscuous protein that not only binds and transports oxygen but is also an enzyme with a peroxidase activity. ${ }^{56} \mathrm{We}$ could furthermore demonstrate that $\mathrm{Hb}$ also possesses "ATRPase" activity. ${ }^{36}$ It catalyzes the homolytic cleavage of $\mathrm{C}-\mathrm{Br}$ bonds to create carbon-centered radicals (which then undergo polymer chain growth in the presence of vinyl monomers). Importantly, it also catalyzes the bromination of polymer radicals to create bromine-terminated polymer chains. Thus, an ATRP equilibrium between propagating radical species and dormant polymer chains is established by $\mathrm{Hb}$, in analogy to conventional ATRP (Scheme 1). ${ }^{36}$ 


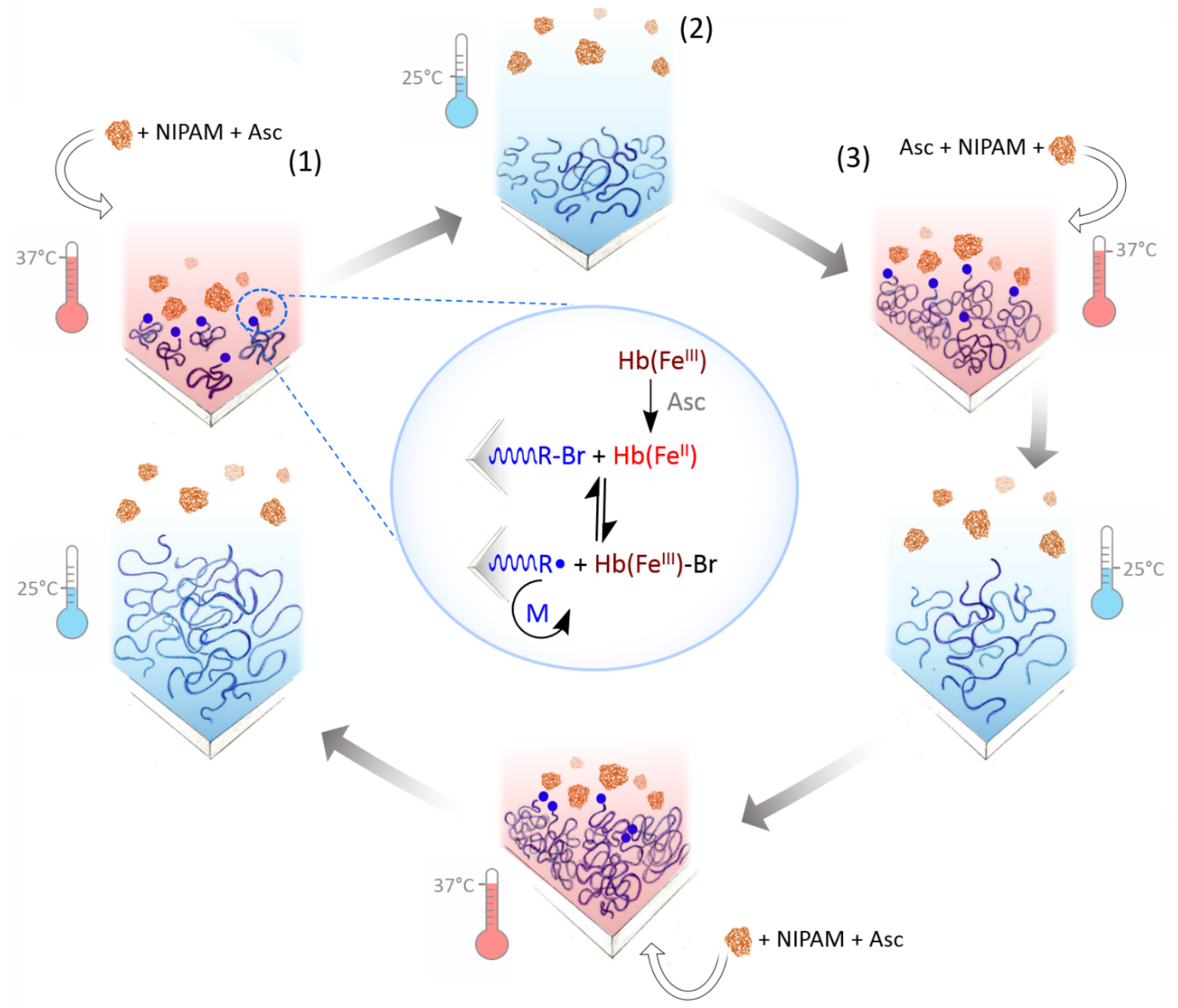

Scheme 1. Schematic representation of multistep SI-bioATRP of NIPAM that shows how SIbioATRP can be controlled by the protein affinity of a polymer brush surface. Grafting of PNIPAM brushes is carried out at $37{ }^{\circ} \mathrm{C}$, i.e., above the polymer's LCST. A collapsed brush conformation allows a close interaction between $\mathrm{Hb}$ and the polymer interface (1). After the polymerization slows down, due to surface passivation by the physisorbed $\mathrm{Hb}$ and increased hindrance of the propagating chain ends, a decrease of the temperature to $25^{\circ} \mathrm{C}$ leads to PNIPAM swelling and the consequent desorption of $\mathrm{Hb}$ from the polymer surface (2). The Hb layer on PNIPAM brushes can be refreshed by injecting a new aliquot of polymerization mixture at $37^{\circ} \mathrm{C}$, thus reinitiating the 
polymerization process (3). Through multiple heating/cooling cycles the thickness of the polymer brushes increases in precise steps, allowing the controlled grafting of thick PNIPAM brushes. The insert shows the bioATRP equilibrium.

Commercial lyophilized $\mathrm{Hb}$ preparations consist of methemoglobin, i.e., the $\mathrm{Fe}(\mathrm{III})$ species, while for the activation of ATRP initiators, protein subunits must be in their Fe(II) state. ${ }^{36}$ Therefore, Hb-catalyzed SI-bioATRP reactions were carried out in the presence of sodium ascorbate (NaAsc). An excess of the reducing agent was used to achieve ARGET ATRP conditions that allow working with a low concentration of the biocatalyst.

In the first set of experiments, the kinetics of Hb-catalyzed bioATRP of PEGA and NIPAM were investigated. Polymerizations were initiated from $\mathrm{TiO}_{2}$ surfaces that were functionalized with an ATRP initiator. The polymerization medium was kept at $25^{\circ} \mathrm{C}$ and the growth of the two different polymer brushes was measured ex situ using variable angle spectroscopic ellipsometry (VASE). PNIPAM films reached a maximum dry thickness of $7.6 \pm 1.5 \mathrm{~nm}$ in $\sim 500$ min of polymerization (Figure 1a). The grafting process stopped within 200-500 min. In a similar way, the dry thickness of PPEGA brushes reached $11.2 \pm 0.7 \mathrm{~nm}$ within $\sim 500 \mathrm{~min}$ (Figure 1b). The formation of the polymer films and their chemical identity was confirmed by contact angle (CA) measurements, Fourier-transform infrared spectroscopy (FTIR), and X-ray photoelectron spectroscopy (XPS) (Supporting Information Figures S3 and S4 and Table S2 and S3). Moreover, the XPS spectra revealed the presence of bromine-bearing chain ends (Figure S5), suggesting that the grafting process was not terminated by irreversible recombination or chain-transfer reactions. A further confirmation that the polymer grafts are in a dormant state came from chain extension experiments using conventional SI-ATRP. Namely, $8.0 \pm 0.2 \mathrm{~nm}$ thick PPEGA brushes synthesized by SI- 
bioATRP were exposed for $1 \mathrm{~h}$ to a solution containing $\mathrm{CuCl}, \mathrm{CuCl}_{2}$, bipyridine, and PEGA, resulting in a $63 \pm 3 \mathrm{~nm}$ thick PPEGA film, as measured using VASE.

The stopping of the grafting process at $25^{\circ} \mathrm{C}$, observed for both PPEGA and PNIPAM brushes, was likely caused by the build-up of protein-repellent coatings on the surfaces. PPEGA brushes are characterized by an intrinsic biopassive character, due to the presence of highly hydrated PEG side chains on each monomer unit. ${ }^{48}$ Similarly, PNIPAM brushes show a biopassive behavior below their LCST, e.g., at $25^{\circ} \mathrm{C}$, due to the hydration of the acrylamide groups along the polymer brush backbone. ${ }^{57,58}$ While the initiator-bearing surface and short polymer chains permit the adsorption of $\mathrm{Hb}$ from the surrounding medium, the polymer layer becomes increasingly protein repellent during chain growth, ${ }^{59}$ until the access of the protein to the dormant chain ends is hindered and the thickness increase of the polymer layers slows down and stops.

The antifouling properties of PNIPAM brushes can be switched off through an increase of the temperature to $37^{\circ} \mathrm{C}$, causing the collapse of the PNIPAM chains and exposure of the hydrophobic domains. ${ }^{57,58}$ Quartz crystal microbalance with dissipation (QCM-D) measurements and atomic force microscopy (AFM) showed that $\mathrm{Hb}$ readily adsorbs to biocatalyically synthesized PNIPAM brushes at $37{ }^{\circ} \mathrm{C}$ but to a much lesser extent at $25{ }^{\circ} \mathrm{C}$ (Figures S6 and S7). Therefore, it should be possible to stimulate Hb-catalyzed SI-bioATRP at higher temperatures. Indeed, when the SIbioATRP of NIPAM was carried out at $37^{\circ} \mathrm{C}$, brush growth proceeded faster, leading to brush films that are $\sim 40 \%$ thicker than PNIPAM brushes synthesized at $25{ }^{\circ} \mathrm{C}$ under otherwise identical conditions (Figure 1a). In contrast, the growth of PPEGA brushes did not vary markedly between these two reaction temperatures (Figure 1b). Thus, the observed increase in the polymerization efficiency of NIPAM at a temperature above PNIPAM's LCST was not primarily due to accelerated ATRP kinetics, as a comparable acceleration would have necessarily affected also the 
grafting of PPEGA. Instead, the enhanced affinity of $\mathrm{Hb}$ toward the PNIPAM brush above the LCST eased the polymerization process and yielded thicker films.

The results of NIPAM polymerizations recorded by ex situ VASE were confirmed by in situ QCMD measurements (Figure S8). After 60 min of polymerization the hydrated mass of PNIPAM brushes reached $367 \pm 4 \mathrm{ng} \mathrm{cm}^{-2}$ at $25^{\circ} \mathrm{C}$ and $1176 \pm 7 \mathrm{ng} \mathrm{cm}^{-2}$ at $37^{\circ} \mathrm{C}$. Using AFM step-height measurements of the dry and swollen PNIPAM films, we could estimate a brush grafting density of $\approx 0.20$ chains $\mathrm{nm}^{-2}$, confirming that SI-bioATRP produced densely grafted polymer layers. ${ }^{60}$ Although physisorption of $\mathrm{Hb}$ on collapsed PNIPAM brushes allowed the synthesis of longer polymer grafts, SI-bioATRP of NIPAM at $37^{\circ} \mathrm{C}$ also ceased within 200 min (Figure 1a). As the polymer brushes could be repeatedly chain extended (vide infra), it is unlikely that the reaction stopped because of irreversible chain termination reactions. NIPAM was present in large excess in the reaction mixtures and addition of further NaAsc to the reaction mixture during the polymerization did not result in thicker polymer films (see Supporting Information for details). Thus, the reactions did not stop because of depletion of reagents. The stopping of SI-bioATRP of NIPAM at $37^{\circ} \mathrm{C}$ was presumably caused by two contributing phenomena. The chain ends of propagating PNIPAM brushes in their collapsed state might become progressively buried within the growing film and therefore become inaccessible for the physisorbed $\mathrm{Hb}$. In addition, $\mathrm{Hb}$ could form a passivating layer on the collapsed brushes that prevented (further) catalytically active $\mathrm{Hb}$ from accessing the dormant chain ends. 
a)

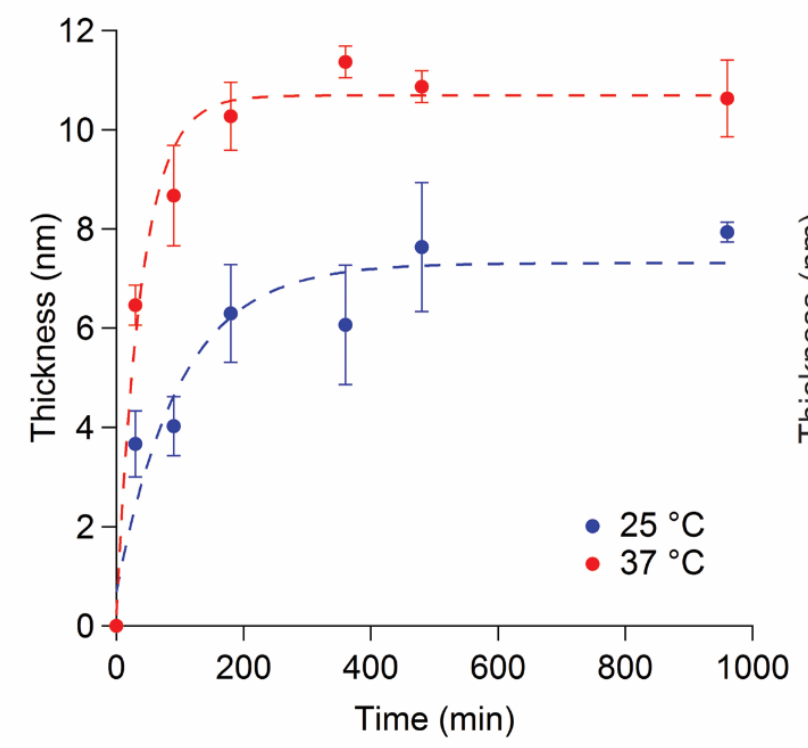

b)

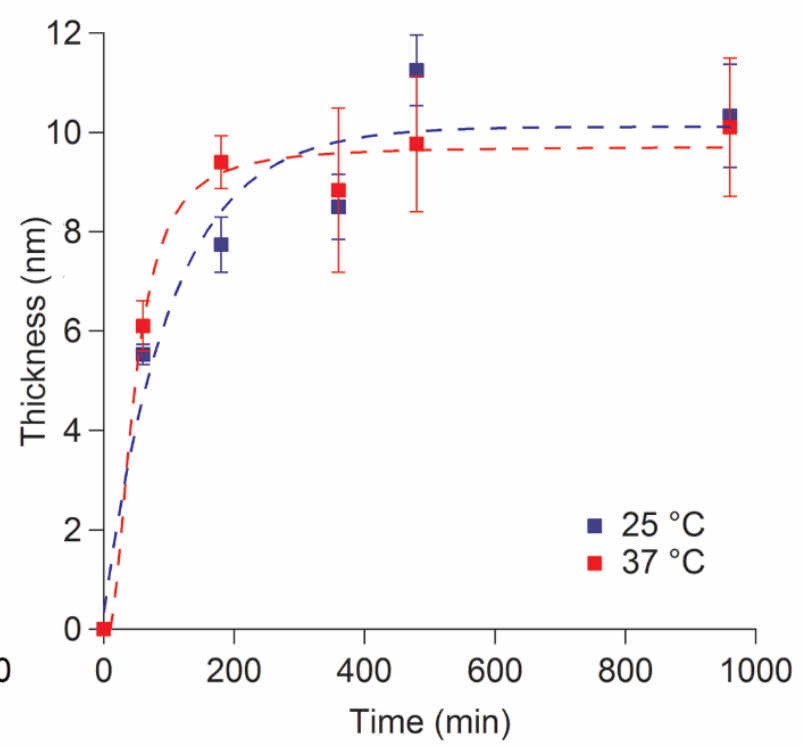

Figure 1. Brush thickening during Hb-catalyzed SI-bioATRP at $25{ }^{\circ} \mathrm{C}$ and $37{ }^{\circ} \mathrm{C}$ at $\mathrm{pH} 4$ as measured using VASE. a) Dry thickness of PNIPAM films vs polymerization time. b) Dry thickness of PPEGA films vs polymerization time. The average and error values (standard deviation) are calculated from a total of $n=9$ data points over three samples, with three thickness measurements on each. The dashed lines are placed to guide the eyes.

To achieve further chain growth and therefore thicker brushes, PNIPAM grafts were synthesized by $1 \mathrm{~h}$ of SI-bioATRP at $37^{\circ} \mathrm{C}$ and then rinsed with cold water. This induced brush swelling and desorption of $\mathrm{Hb}$. Subsequent incubation in a new aliquot of polymerization solution kept at $37{ }^{\circ} \mathrm{C}$ led to the reinitiation of SI-bioATRP (Figure 2a and Scheme 1). After one additional hour of reaction, the dry thickness of PNIPAM brushes was doubled, confirming that the dormant chain ends were again accessible at the surface and that further enzyme-mediated growth of the polymer chains occurred. By repeating this procedure several times, PNIPAM brushes were grown step- 
by-step in a controlled fashion with a linear increase in polymer brush thickness by $4.3 \pm 0.2 \mathrm{~nm}$ (from linear regression to the VASE data; $R^{2}=0.99$ ) after each rinsing/polymerization cycle (Figure 4a and Scheme 1). It is important to note that linear thickening rates during the synthesis of polymer brushes by SI-ATRP suggest a well-controlled radical polymerization. ${ }^{14}$

When similar polymerization steps were carried out at $25{ }^{\circ} \mathrm{C}$, the thickness of the generated PNIPAM brush also increased stepwise, but with a lower rate $(1.4 \pm 0.2 \mathrm{~nm}$ of thickening during each polymerization/rinsing step; $R^{2}=0.93$ ). These results demonstrated again that PNIPAM grafting was hindered and the film thickening was slowed down when the brush surface was in its swollen and biopassive state.

The multistep SI-bioATRP of NIPAM was also monitored in situ using QCM-D (Figure 2b). Each polymerization step at $37^{\circ} \mathrm{C}$ resulted in a progressive decrease of $\Delta f$, confirming the efficient grafting of PNIPAM brushes above the LCST. In contrast, when multiple reinitiations were carried out at $25^{\circ} \mathrm{C}$, much smaller decreases of $\Delta f$ were recorded for each step, corroborating the results obtained using ex situ VASE.

A similar multistep grafting was performed with PEGA brushes, applying SI-bioATRP at $37^{\circ} \mathrm{C}$ and $25^{\circ} \mathrm{C}$, and rinsing steps at $25^{\circ} \mathrm{C}$. In the first polymerization step of $1 \mathrm{~h}$, a film of approximately $5 \mathrm{~nm}$ dry thicknesses formed, as measured using VASE. Then, the dry thickness of PPEGA brushes increased by $0.7 \pm 0.1 \mathrm{~nm}\left(R^{2}=0.97\right)$ with each polymerization step (Figure $2 \mathrm{c}$ ). The brush thickening was independent of the polymerization temperature within the error margin of the measurements. A similar result was obtained by QCM-D (Figure 2d). The first SI-bioATRP of PEGA resulted in the largest decrease of $\Delta f$, each of the following polymerization steps showed a modest decay in $\Delta f$. Thus, these results further confirm that, initially, the grafting polymerization proceeds well because the surface is not yet protein repellent. In the subsequent polymerization 
steps, the protein-repellent properties of the PPEGA brushes hinder the access of $\mathrm{Hb}$ to the dormant chain ends, resulting in slow polymer grafting. The fact that temperature had no effect on the PEGA polymerization indicates that the observed temperature-induced differences in NIPAM polymerization do not stem from a higher polymerization rate at higher temperature but from the switchable protein repellency of the PNIPAM surfaces.

a)

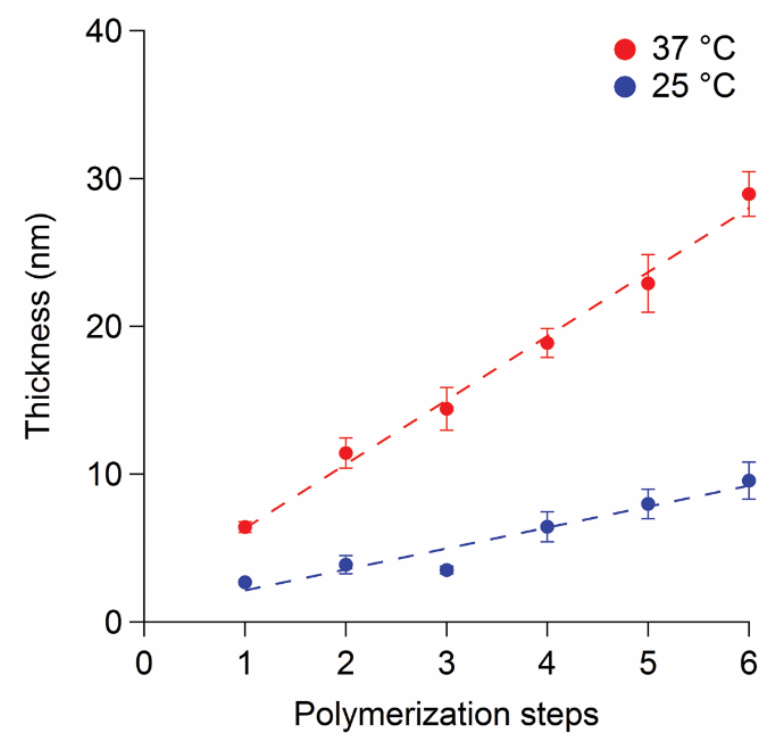

c)

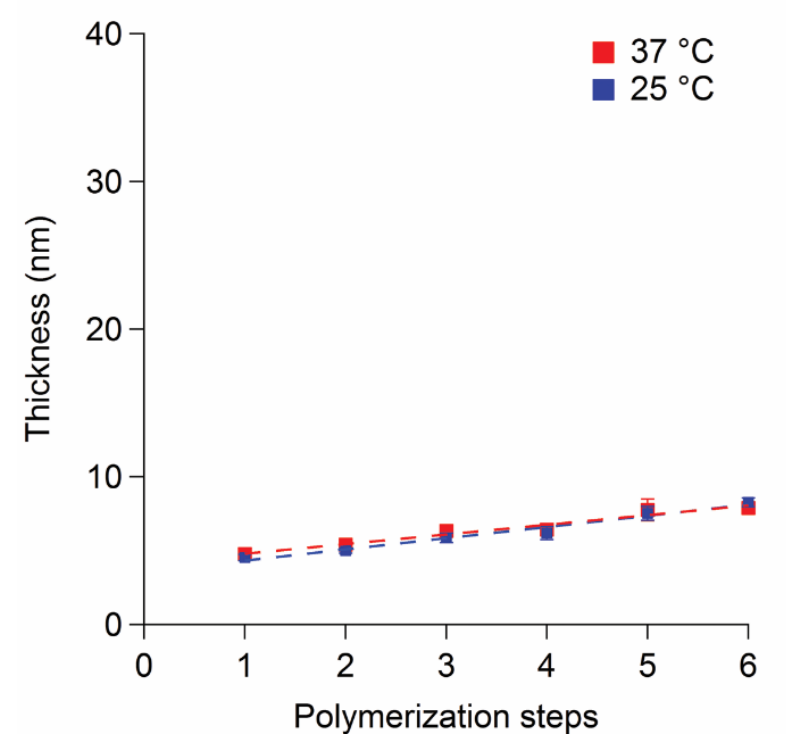

b)

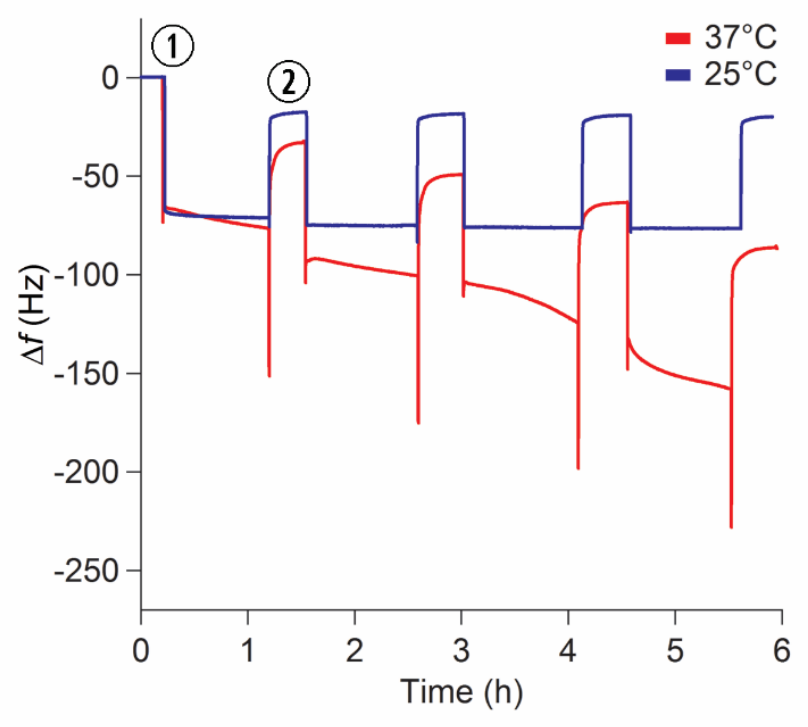

d)

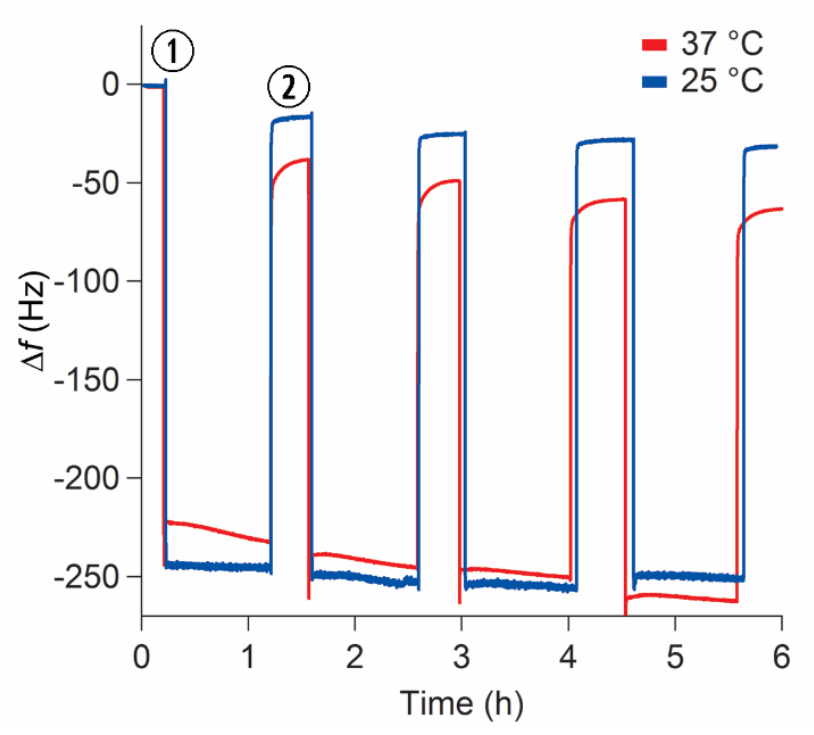


Figure 2. Synthesis of polymer brushes with well-defined thickness by SI-bioATRP through multiple reinitiation/rinsing steps. a), b) PNIPAM brush thickening at $37{ }^{\circ} \mathrm{C}$ and $25{ }^{\circ} \mathrm{C}$ at $\mathrm{pH} 4$ as measured using ex situ VASE and in situ QCM-D. c), d) PPEGA brush thickening at $37{ }^{\circ} \mathrm{C}$ and $25^{\circ} \mathrm{C}$ at $\mathrm{pH} 4$ as measured using ex situ VASE and in situ QCM-D. The lines in (a) and (c) correspond to linear fits to the VASE film-thickening data. The average and error values (standard deviation) are calculated from $n=9$ data points over three samples, with three thickness measurement points on each. The QCM-D sensograms start with a stable baseline (1) recorded in ultra-pure water, followed by the first SI-bioATRP step and, after $1 \mathrm{~h}$ of polymerization, a rinsing step using ultra-pure water at room temperature (2). The variation of $\Delta f$ between (1) and (2) correlates with the change in hydrated polymer mass on the sensor.

To prove the versatility and controlled character of SI-bioATRP, block-copolymerization of NIPAM from PPEGA brushes was carried out. To this end, $6.2 \pm 0.3 \mathrm{~nm}$ thick PPEGA brushes were synthesized using SI-bioATRP at $25{ }^{\circ} \mathrm{C}$ in one step of $1 \mathrm{~h}$ (Figure 3). The surface was rinsed with water at room temperature and dried. Subsequently, the sample was incubated at $37{ }^{\circ} \mathrm{C}$ in a solution of NIPAM, NaAsc, and $\mathrm{Hb}$ for $1 \mathrm{~h}$. Following this chain extension step, VASE indicated an increase in brush dry thickness of $2.5 \pm 0.5 \mathrm{~nm}$, suggesting the successful synthesis of PPEGA$b$-PNIPAM brushes. Remarkably, further reinitiation/rinsing steps allowed to chain extend polymer with at least four more PNIPAM blocks. The thickness of the polymer layer increased linearly, yielding $24.1 \pm 0.9 \mathrm{~nm}$ thick films after five sequential SI-bioATRP reactions at $37^{\circ} \mathrm{C}$. When the sequential NIPAM polymerizations were carried out at $25^{\circ} \mathrm{C}$, PNIPAM blocks formed, but the PPEGA- $b$-PNIPAM brushes only reached a dry thickness of $11.9 \pm 0.7 \mathrm{~nm}$ after the same number of steps. These results allow concluding that it was possible to reinitiate the protein- 
repellent PPEGA brushes using Hb. Moreover, once the first NIPAM block was formed on the PPEGA, subsequent polymerization steps were governed by the protein adsorption properties of PNIPAM.

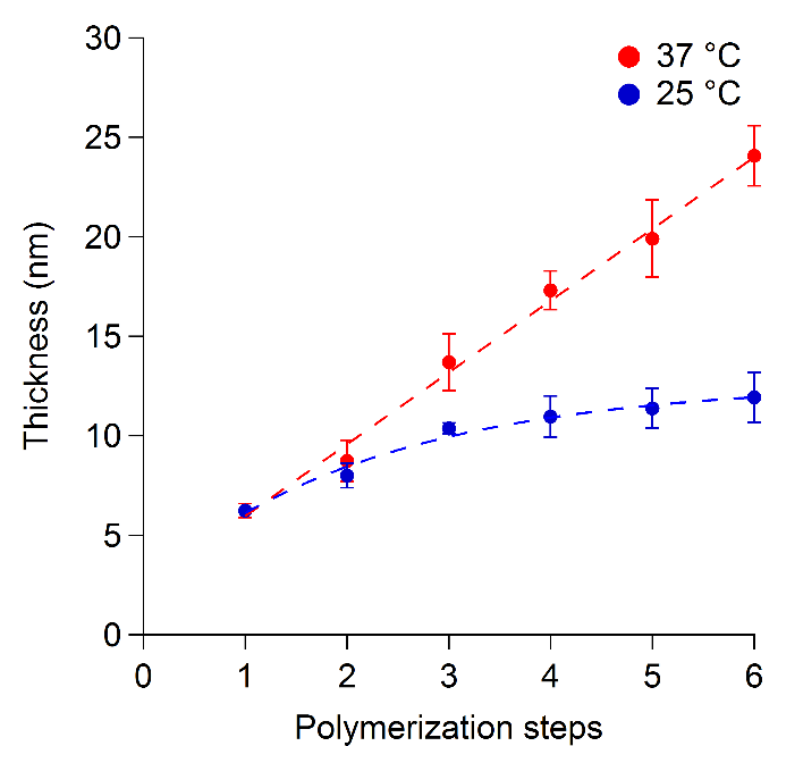

Figure 3. Synthesis of PPEGA- $b$-PNIPAM brushes by sequential SI-bioATRP of PEGA at $25^{\circ} \mathrm{C}$ (step 1), followed by NIPAM polymerization/rinsing cycles at $37^{\circ} \mathrm{C}$ and $25^{\circ} \mathrm{C}$ as measured using VASE. All polymerizations were carried out at $\mathrm{pH} 4$ and all rinsing steps with water at $25^{\circ} \mathrm{C}$. The average and error values (standard deviation) are calculated from $n=9$ data points over three samples, with three thickness measurement points on each.

\section{Effects of pH on SI-bioATRP}

The polymerizations described above were carried out using solutions that were buffered at $\mathrm{pH} 4$. We previously demonstrated this to be the best condition for obtaining low polydispersities and high conversions in the solution-based Hb-catalyzed ATRP of NIPAM ${ }^{36}$ However, it is well known that variations of $\mathrm{pH}$ induce structural changes of $\mathrm{Hb}$ and have an effect on the protein's 
catalytic activity. ${ }^{61}$ In particular, heme proteins undergo a transition between their folded native state and a molten globular state when the $\mathrm{pH}$ is shifted below $4 .{ }^{62-64}$ Protonation of the protein's histidines causes the heme group to lose its binding with the proximal histidine so that the iron center becomes a four-coordinate species and the heme pocket of the protein enlarges ${ }^{65,66}$ Thus, the heme groups are more accessible from the surrounding medium, which was reported to result in higher oxidase and peroxidase activities. ${ }^{65,66}$ In order to assess whether an acid-induced variation of $\mathrm{Hb}$ structure also influenced the SI-bioATRP process, the grafting of NIPAM by multiple reinitiation/rinsing steps was carried out at $\mathrm{pH}$ values between 3 and 5 . When the reaction temperature was $37^{\circ} \mathrm{C}$, PNIPAM brushes grew thicker per polymerization step at $\mathrm{pH} 3$ and 4 than at $\mathrm{pH} 5$ (Figure 4a). In contrast, the $\mathrm{pH}$ had no remarkable effect on polymerizations that were performed at $25^{\circ} \mathrm{C}$ (Figure S10). It is likely that under acidic conditions the conformation of $\mathrm{Hb}$ enhanced the polymerization on protein adherent surfaces, while the biopassive property of PNIPAM brushes at room temperature hindered the access of $\mathrm{Hb}$ to the dormant chains irrespective of the protein's conformation.

UV-vis spectroscopy revealed the influence of the polymerization mixture and its $\mathrm{pH}$ on the interaction of the heme groups with their binding pockets (Figure 4b and Figures S11 and S12). The spectrum of $\mathrm{Hb}$ at $\mathrm{pH} 4$, prior to exposure to the polymerization mixture, is characterized by a strong Soret band centered at $406 \mathrm{~nm}$ and two minor signals at 500 and $630 \mathrm{~nm}$. The spectrum is typical of methemoglobin. The characteristic UV-vis pattern of the protein changed when $\mathrm{Hb}$ was exposed under aerobic conditions to solutions of NIPAM and NaAsc buffered to $\mathrm{pH}$ values between 5 and 3. At $\mathrm{pH}$, the Soret band remained at $406 \mathrm{~nm}$ and the absorption bands in the vis region shifted to $500 \mathrm{~nm}, 536 \mathrm{~nm}, 578 \mathrm{~nm}$, and $630 \mathrm{~nm}$. This pattern is indicative of oxygenated $\mathrm{Hb}$, in which the protein maintained its native conformation and the heme groups of the $\beta$-subunits 
were reduced to $\mathrm{Fe}(\mathrm{II})$, while the heme groups of the $\alpha$-subunits remained in their $\mathrm{Fe}(\mathrm{III})$ state. ${ }^{67}$ This so-called intermediate $\mathrm{Hb}$ formed because NaAsc is a relatively weak reducing agent that only reduces the iron of the $\beta$-subunits of methemoglobin. ${ }^{67} \mathrm{At} \mathrm{pH} 4$, the intensity of the Soret band at $406 \mathrm{~nm}$ decreased upon exposure of the protein to monomer and reducing agent, which was accompanied by the formation of an additional band centered at $368 \mathrm{~nm}$. The coexistence of these two bands suggests the presence of two different $\mathrm{Hb}$ species. The peak at $406 \mathrm{~nm}$ is indicative of the native form of $\mathrm{Hb}$, while the new band at $368 \mathrm{~nm}$ corresponds to the partially unfolded protein, presumably in a molten globular state.$^{66}$ This transition became more pronounced when the $\mathrm{pH}$ of the polymerization mixture was lowered to 3 . The spectrum mainly shows the peak related to the acidic conformation of $\mathrm{Hb}$ at $368 \mathrm{~nm}$, and only a weak shoulder at $406 \mathrm{~nm}$. It should be noted that the transition of the $\mathrm{Hb}$ to its acidic conformation is facilitated by the high concentration of monomer in the solution, because in the absence of this reagent the protein had a stable, native-like UV-vis spectrum at pH 4 (Supporting Information Figures S12-S15).

The $\mathrm{pH}$-induced structural transitions of $\mathrm{Hb}$ were found to be reversible, as demonstrated by experiments where the $\mathrm{pH}$ of the polymerization solution was decreased to 3 and then brought back to $\mathrm{pH} 6$ (Figure 4c). The increase of the $\mathrm{pH}$ caused the Soret band of the molten globule at $368 \mathrm{~nm}$ to decrease. Concurrently, the peak at $406 \mathrm{~nm}$ increased until the UV-vis spectrum of oxygenated intermediate $\mathrm{Hb}$ was obtained. Thus, the native conformation of $\mathrm{Hb}$ was recovered, which confirms that no irreversible denaturation of the protein occurred at low $\mathrm{pH}$. These results also rule out that heme detached from the protein under acidic conditions. Otherwise it would be unlikely that the acid-induced changes around the heme group are reversible.

Further proof that the protein retained a substantial degree of secondary structure at low $\mathrm{pH}$ even though it underwent significant conformational changes came from circular dichroism (CD) 
spectroscopy (Figure S16). At $\mathrm{pH} 5$, the spectrum was typical for the native structure of $\mathrm{Hb}$, which is rich in $\alpha$-helices. The $\mathrm{CD}$ spectrum at $\mathrm{pH} 2.5$ revealed a mixture of $\alpha$-helices and random coils. Taken together, the $\mathrm{pH}$-dependent polymerization and spectroscopic results suggest that the acidic conformation allowed for better access of the polymer chain ends to the active site, favoring a more intimate contact between the catalyst and the growing chains, and therefore accelerating the grafting process. This conclusion is consistent with the notion that heme is more accessible in the molten globule state of $\mathrm{Hb}$. Moreover, our results are in agreement with previous observations that the catalytic activity of $\mathrm{Hb}$ is higher at acidic conditions. ${ }^{65,67}$

a)

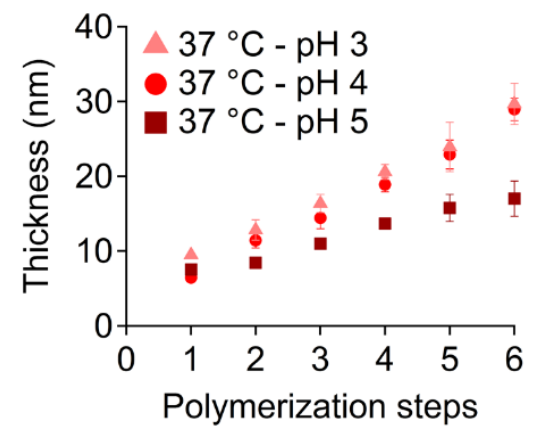

b)

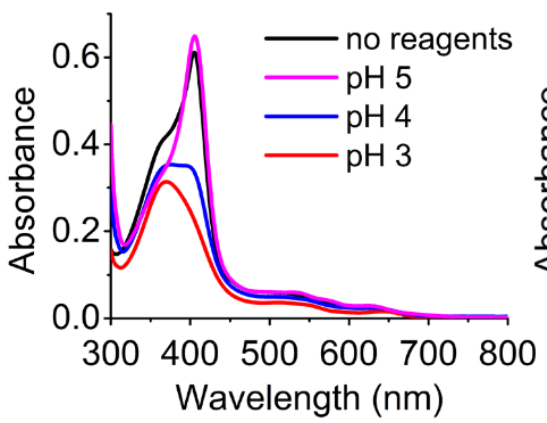

c)

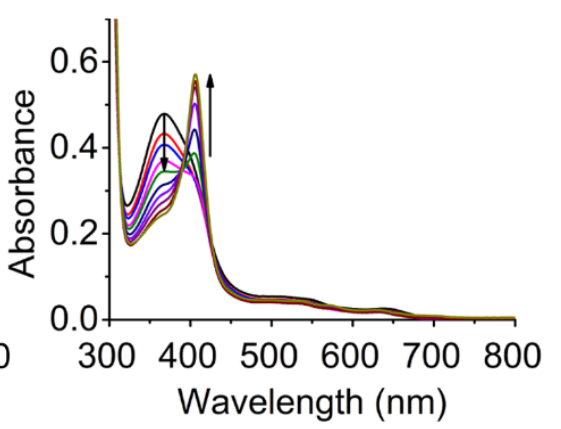

Figure 4. Influence of $\mathrm{pH}$ on SI-bioATRP of NIPAM at $37{ }^{\circ} \mathrm{C}$ and on the conformation of $\mathrm{Hb}$. a) PNIPAM brush thickening during multistep SI-bioATRP at $37{ }^{\circ} \mathrm{C}$ performed at different $\mathrm{pH}$ values, as measured ex situ using VASE. The average and error values (standard deviation) are calculated from $n=9$ data points over three samples, with three thickness measurement points on each. b) UV-vis spectra of $\mathrm{Hb}$ after incubation for $1 \mathrm{~h}$ at $37{ }^{\circ} \mathrm{C}$ at $\mathrm{pH} 4$ in the absence of reagents (black trace) and in solutions of different $\mathrm{pH}$ that contained NIPAM $(567.8 \mathrm{mM})$ and NaAsc $(8.5$ $\mathrm{mM}$ ) at polymerization concentrations. c) UV-vis spectra of $\mathrm{Hb}$ in the presence of NIPAM (567.8 $\mathrm{mM})$ and NaAsc $(8.5 \mathrm{mM})$ at polymerization concentrations at $25{ }^{\circ} \mathrm{C}$ with a gradual increase in $\mathrm{pH}$ (from 3 to 6) by the addition of $20 \mu \mathrm{L}$ of $0.4 \mathrm{M} \mathrm{NaOH}$. pH 3.87 (black), pH 4.08 (red), pH 4.26 
(blue), pH 4.41 (pink), pH 4.57 (green), pH 4.72 (dark blue), pH 4.90 (violet), pH 5.11 (purple), pH 5.38 (brown), pH 5.86 (gold).

\section{Conclusions}

We demonstrate that Hb-catalyzed SI-bioATRP allows the fabrication of polymer and blockcopolymer brushes in a highly controlled fashion when the bioaffinity of the modified surfaces can be precisely governed. While protein-repellent PPEGA brushes only increased slowly in thickness, PNIPAM layers were efficiently grown following a multistep polymerization protocol. Polymerization was stimulated at $37^{\circ} \mathrm{C}$ by the adsorption of $\mathrm{Hb}$ on the collapsed PNIPAM surface, while at $25^{\circ} \mathrm{C}$ brush swelling induced the detachment of the physisorbed proteins and enabled the renewal of the catalyst layer after a further increase of the temperature above LCST. Moreover, the overall rate of multistep SI-bioATRP could be further modulated by varying the $\mathrm{pH}$ of the reaction medium, directly altering the accessibility of the catalytic heme pocket within the $\mathrm{Hb}$ tertiary structure.

Under optimized polymerization conditions, multistep SI-bioATRP produced a constant increment of brush thickness with each polymerization step, which enables to dial-in a predefined layer's growth by simply performing SI-bioATRP for a predetermined number of steps and allows the synthesis of multiblock copolymers on surfaces. This result highlights the synthetic potential of SI-bioATRP, since conventional SI-ATRP in fully aqueous conditions is often hampered by radical termination reactions and catalyst decomposition. 
In a more general sense, we demonstrate how the biocatalytic synthesis of polymers from surfaces can be precisely controlled through the modulation of the interfacial physicochemical properties, in particular of the surface's affinity toward proteins. These findings suggest a new way to exploit interactions between surfaces and catalytically active biomolecules for the controlled functionalization of materials. As an example, the functionalization of biomaterials by polymer grafting could be performed in vitro, in the presence of cells and under fully biocompatible conditions. Alternatively, the exposed surface of functional implants could be decorated in vivo, by applying polymerizable species and in the presence of catalytically active biomolecules.

\section{ASSOCIATED CONTENT}

Supporting Information. Further characterization of PPEGA and PNIPAM brushes is provided in the Supporting Information, including FTIR, AFM and XPS.

\section{AUTHOR INFORMATION}

Corresponding Authors

* Dr. Edmondo M. Benetti, Laboratory for Surface Science and Technology, Department of Materials, ETH Zürich, Vladimir-Prelog-Weg 1.5/10, 8093 Switzerland.

Email: edmondo.benetti@mat.ethz.ch

* Prof. Nico Bruns, Adolphe Merkle Institute, Chemin des Verdiers 4, CH-1700 Fribourg, Switzerland.

Email: nico.bruns@unifr.ch

\section{ACKNOWLEDGMENTS}


We thank Prof. Antonella Rossi, Mr. Giovanni Cossu and Prof. Nicholas D. Spencer (ETH Zürich) for the fruitful discussions. This work was financed by the Swiss National Science Foundation through a SNSF Professorship to N.B. (grant number PP00P2_144697) and an Ambizione fellowship to E.M.B. (PZ00P2-790148156).

\section{References:}

(1) Kingshott, P.; Andersson, G.; McArthur, S. L.; Griesser, H. J. Surface Modification and Chemical Surface Analysis of Biomaterials. Curr. Opin. Chem. Biol. 2011, 15 (5), 667676.

(2) Wu, G.; Li, P.; Feng, H.; Zhang, X.; Chu, P. K. Engineering and Functionalization of Biomaterials via Surface Modification. J. Mater. Chem. B 2015, 3 (10), 2024-2042.

(3) Lutolf, M. P.; Hubbell, J. A. Synthetic Biomaterials as Instructive Extracellular Microenvironments for Morphogenesis in Tissue Engineering. Nat. Biotechnol. 2005, 23 (1), 47-55.

(4) Raynor, J. E.; Capadona, J. R.; Collard, D. M.; Petrie, T. A.; García, A. J. Polymer Brushes and Self-Assembled Monolayers: Versatile Platforms to Control Cell Adhesion to Biomaterials (Review). Biointerphases 2009, 4 (2), FA3.

(5) Senaratne, W.; Andruzzi, L.; Ober, C. K. Self-Assembled Monolayers and Polymer Brushes in Biotechnology: Current Applications and Future Perspectives.

Biomacromolecules 2005, 6 (5), 2427-2448.

(6) Falconnet, D.; Csucs, G.; Michelle Grandin, H.; Textor, M. Surface Engineering Approaches to Micropattern Surfaces for Cell-Based Assays. Biomaterials 2006, 27 (16), 3044-3063. 
(7) Ho, C. H.; Tobis, J.; Sprich, C.; Thomann, R.; Tiller, J. C. Nanoseparated Polymeric Networks with Multiple Antimicrobial Properties. Adv. Mater. 2004, 16 (12), 957-961.

(8) Reimhult, E.; Höök, F. Design of Surface Modifications for Nanoscale Sensor Applications. Sensors 2015, 15 (1), 1635-1675.

(9) Milner, S. T. Polymer Brushes. Science 1991, 251 (4996).

(10) Barbey, R. R. R.; Lavanant, L.; Paripovic, D.; Schüwer, N.; Sugnaux, C.; Tugulu, S.; Klok, H.-A.; Schüwer, N.; Sugnaux, C.; Tugulu, S.; et al. Polymer Brushes via SurfaceInitiated Controlled Radical Polymerization: Synthesis, Characterization, Properties, and Applications. Chem. Rev. 2009, 109 (11), 5437-5527.

(11) Edmondson, S.; Osborne, V. L.; Huck, W. T. S. Polymer Brushes via Surface-Initiated Polymerizations. Chem. Soc. Rev. 2004, 33 (1), 14.

(12) Zoppe, J. O.; Ataman, N. C.; Mocny, P.; Wang, J.; Moraes, J.; Klok, H. A. SurfaceInitiated Controlled Radical Polymerization: State-of-the-Art, Opportunities, and Challenges in Surface and Interface Engineering with Polymer Brushes. Chem. Rev. 2017, $117(3), 1105-1318$.

(13) Pyun, J.; Kowalewski, T.; Matyjaszewski, K. Synthesis of Polymer Brushes Using Atom Transfer Radical Polymerization. Macromol. Rapid Commun. 2003, 24 (18), 1043-1059.

(14) Husseman, M.; Malmström, E. Controlled Synthesis of Polymer Brushes by "living” Free Radical Polymerization Techniques. Macromolecules 1999, 32, 1424-1431.

(15) Baum, M.; Brittain, W. J. Synthesis of Polymer Brushes on Silicate Substrates via Reversible Addition Fragmentation Chain Transfer Technique. Macromolecules 2002, 35 (3), 610-615.

(16) Zavada, S. R.; Battsengel, T.; Scott, T. F. Radical-Mediated Enzymatic Polymerizations. 
Int. J. Mol. Sci. 2016, 17 (2).

(17) Shoda, S. I.; Uyama, H.; Kadokawa, J. I.; Kimura, S.; Kobayashi, S. Enzymes as Green Catalysts for Precision Macromolecular Synthesis. Chem. Rev. 2016, 116 (4), 2307-2413.

(18) Hollmann, F.; Arends, I. W. C. E. Enzyme Initiated Radical Polymerizations; 2012; Vol. 4.

(19) Kim, Y. R.; Paik, H. J.; Ober, C. K.; Coates, G. W.; Batt, C. A. Enzymatic SurfaceInitiated Polymerization: A Novel Approach for the in Situ Solid-Phase Synthesis of Biocompatible Polymer pol(3-Hydroxybutyrate). Biomacromolecules 2004, 5 (3), 889894.

(20) Kim, Y.; Paik, H.; Ober, C. K.; Coates, G. W.; Mark, S. S.; Ryan, T. E.; Batt, C. A. RealTime Analysis of Enzymatic Surface-Initiated Polymerization Using Surface Plasmon Resonance (SPR). Macromol. Biosci. 2006, 6 (2), 145-152.

(21) Li, J.; Xie, W.; Cheng, H. N.; Nickol, R. G.; Wang, P. G. Polycaprolactone-Modified Hydroxyethylcellulose Films Prepared by Lipase-Catalyzed Ring-Opening Polymerization. Macromolecules 1999, 32 (8), 2789-2792.

(22) Matsumura, S. Enzymatic Synthesis of Polyesters via Ring-Opening Polymerization. In Enzyme-Catalyzed Synthesis of Polymers; Kobayashi, S., Ritter, H., Kaplan, D., Eds.; Springer Berlin Heidelberg: Berlin, Heidelberg, 2006; pp 95-132.

(23) Guo, Z.; Hauser, N.; Moreno, A.; Ishikawa, T.; Walde, P. AOT Vesicles as Templates for the Horseradish Peroxidase-Triggered Polymerization of Aniline. Soft Matter 2011, 7 (1), $180-193$.

(24) Guo, Z.; Rüegger, H.; Kissner, R.; Ishikawa, T.; Willeke, M.; Walde, P. Vesicles as Soft Templates for the Enzymatic Polymerization of Aniline. Langmuir 2009, 25 (19), 11390- 
11405.

(25) Junker, K.; Zandomeneghi, G.; Guo, Z.; Kissner, R.; Ishikawa, T.; Kohlbrecher, J.; Walde, P. Mechanistic Aspects of the Horseradish Peroxidase-Catalysed Polymerisation of Aniline in the Presence of AOT Vesicles as Templates. RSC Adv. 2012, 2 (16), 6478.

(26) Walde, P.; Guo, Z. Enzyme-Catalyzed Chemical Structure-Controlling Template Polymerization. Soft Matter 2011, 7 (2), 316-331.

(27) Fukushima, H.; Kohri, M.; Kojima, T.; Taniguchi, T.; Saito, K.; Nakahira, T. SurfaceInitiated Enzymatic Vinyl Polymerization: Synthesis of Polymer-Grafted Silica Particles Using Horseradish Peroxidase as Catalyst. Polym. Chem. 2012, 3 (5), 1123.

(28) Kohri, M. Development of HRP-Mediated Enzymatic Polymerization under Heterogeneous Conditions for the Preparation of Functional Particles. Polym. J. 2014, 46 (7), 373-380.

(29) Tjong, V.; Yu, H.; Hucknall, A.; Chilkoti, A. Direct Fluorescence Detection of RNA on Microarrays by Surface-Initiated Enzymatic Polymerization. Anal. Chem. 2013, 85 (1), $426-433$.

(30) Wan, Y.; Xu, H.; Su, Y.; Zhu, X.; Song, S.; Fan, C. A Surface-Initiated Enzymatic Polymerization Strategy for Electrochemical DNA Sensors. Biosens. Bioelectron. 2013, $41(1), 526-531$.

(31) Tjong, V.; Yu, H.; Hucknall, A.; Rangarajan, S.; Chilkoti, A. Amplified On-Chip Fluorescence Detection of DNA Hybridization by Surface-Initiated Enzymatic Polymerization. Anal. Chem. 2011, 83 (13), 5153-5159.

(32) Hu, W.; Ning, Y.; Kong, J.; Zhang, X. Formation of Copper Nanoparticles on Poly(thymine) through Surface-Initiated Enzymatic Polymerization and Its Application for 
DNA Detection. Analyst 2015, 140 (16), 5678-5684.

(33) Lin, D.; Mei, C.; Liu, A.; Jin, H.; Wang, S.; Wang, J. Cascade Signal Amplification for Electrochemical Immunosensing by Integrating Biobarcode Probes, Surface-Initiated Enzymatic Polymerization and Silver Nanoparticle Deposition. Biosens. Bioelectron. 2015, 66, 177-183.

(34) Mei, C.; Lin, D.; Fan, C.; Liu, A.; Wang, S.; Wang, J. Highly Sensitive and Selective Electrochemical Detection of $\mathrm{Hg} 2+$ through Surface-Initiated Enzymatic Polymerization. Biosens. Bioelectron. 2016, 80, 105-110.

(35) Sigg, S. J.; Seidi, F.; Renggli, K.; Silva, T. B.; Kali, G.; Bruns, N. ATRPases: Enzymes as Catalysts for Atom Transfer Radical Polymerization. Chim. Int. J. Chem. 2012, 66 (1), 66-66.

(36) Silva, T. B.; Spulber, M.; Kocik, M. K.; Seidi, F.; Charan, H.; Rother, M.; Sigg, S. J.; Renggli, K.; Kali, G.; Bruns, N. Hemoglobin and Red Blood Cells Catalyze Atom Transfer Radical Polymerization. Biomacromolecules 2013, 14 (8), 2703-2712.

(37) Fodor, C.; Gajewska, B.; Rifaie-Graham, O.; Apebende, E. A.; Pollard, J.; Bruns, N. Laccase-Catalyzed Controlled Radical Polymerization of N-Vinylimidazole. Polym. Chem. 2016, 7 (43), 6617-6625.

(38) Dinu, M. V.; Spulber, M.; Renggli, K.; Wu, D.; Monnier, C. A.; Petri-Fink, A.; Bruns, N. Filling Polymersomes with Polymers by Peroxidase-Catalyzed Atom Transfer Radical Polymerization. Macromol. Rapid Commun. 2015, 36 (6), 507-514.

(39) Ng, Y.-H.; di Lena, F.; Chai, C. L. L. Metalloenzymatic Radical Polymerization Using Alkyl Halides as Initiators. Polym. Chem. 2011, 2 (3), 589-594.

(40) Ng, Y.-H.; di Lena, F.; Chai, C. L. L. PolyPEGA with Predetermined Molecular Weights 
from Enzyme-Mediated Radical Polymerization in Water. Chem. Commun. 2011, 47 (22), 6464-6466.

(41) Renggli, K.; Sauter, N.; Rother, M.; Nussbaumer, M. G.; Urbani, R.; Pfohl, T.; Bruns, N. Biocatalytic Atom Transfer Radical Polymerization in a Protein Cage Nanoreactor. Polym. Chem. 2017, 8 (14), 2133-2136.

(42) Simakova, A.; Mackenzie, M.; Averick, S. E.; Park, S.; Matyjaszewski, K. Bioinspired Iron-Based Catalyst for Atom Transfer Radical Polymerization. Angew. Chemie - Int. Ed. 2013, 52 (46), 12148-12151.

(43) Gao, G.; Karaaslan, M. A.; Kadla, J. F.; Ko, F. Enzymatic Synthesis of Ionic Responsive Lignin Nanofibres through Surface poly(N-Isopropylacrylamide) Immobilization. Green Chem. 2014, 16 (8), 3890-3898.

(44) Sun, Y.; Du, H.; Lan, Y.; Wang, W.; Liang, Y.; Feng, C.; Yang, M. Preparation of Hemoglobin ( $\mathrm{Hb})$ Imprinted Polymer by Hb Catalyzed eATRP and Its Application in Biosensor. Biosens. Bioelectron. 2016, 77, 894-900.

(45) Materials, N.; Issue, S.; Res, A. C.; Jones, B. D. M.; Smith, J. R.; Huck, W. T. S.; Alexander, C. Variable Adhesion of Micropatterned Thermoresponsive of. 2002, No. 16, $1130-1134$.

(46) Mendez, S.; Subramanian, B.; Balamurugan, S. S.; O’Brien, M. J.; Lopez, G. P. LCST Phase Behavior of End-Grafted poly(N-Isopropylacrylamide). Abstr. Pap. Am. Chem. Soc 2003, 225, U617-U617.

(47) Benetti, E. M.; Zapotoczny, S.; Vancso, G. J. Tunable Thermoresponsive Polymeric Platforms on Gold By “photoiniferter”-Based Surface Grafting. Adv. Mater. 2007, 19 (2), 268-271. 
(48) Ma, H.; Hyun, J.; Stiller, P.; Chilkoti, A. "Non-Fouling”' Oligo(ethylene Glycol)Functionalized Polymer Brushes Synthesized by Surface-Initiated Atom Transfer Radical Polymerization. Adv. Mater. 2004, 16 (4), 338-341.

(49) Kim, J.-B.; Huang, W.; Miller, M. D.; Baker, G. L.; Bruening, M. L. Kinetics of SurfaceInitiated Atom Transfer Radical Polymerization. J. Polym. Sci. Part A Polym. Chem. 2003, 41 (3), 386-394.

(50) Bortolamei, N.; Isse, A. A.; Magenau, A. J. D.; Gennaro, A.; Matyjaszewski, K. Controlled Aqueous Atom Transfer Radical Polymerization with Electrochemical Generation of the Active Catalyst. Angew. Chemie Int. Ed. 2011, 50 (48), 11391-11394.

(51) Coullerez, G.; Carlmark, A.; Malmström, E.; Jonsson, M. Understanding Copper-Based Atom-Transfer Radical Polymerization in Aqueous Media. J. Phys. Chem. A 2004, 108 (35), 7129-7131.

(52) Tsarevsky, N. V.; Pintauer, T.; Matyjaszewski, K. Deactivation Efficiency and Degree of Control over Polymerization in ATRP in Protic Solvents. Macromolecules 2004, 37 (26), 9768-9778.

(53) Malisova, B.; Tosatti, S.; Textor, M.; Gademann, K.; Zürcher, S. Poly(ethylene Glycol) Adlayers Immobilized to Metal Oxide Substrates Through Catechol Derivatives: Influence of Assembly Conditions on Formation and Stability. Langmuir 2010, 26 (6), 4018-4026.

(54) Hilfiker, J. N.; Synowicki, R. A. Spectroscopic Ellipsometry for Polymer Thin Films. Solid State Technol. 1998, 41 (10), 101-110.

(55) Reimhult, E.; Larsson, C.; Kasemo, B.; Höök, F. Simultaneous Surface Plasmon Resonance and Quartz Crystal Microbalance with Dissipation Monitoring Measurements of Biomolecular Adsorption Events Involving Structural Transformations and Variations 
in Coupled Water. Anal. Chem. 2004, 76 (24), 7211-7220.

(56) Reeder, B. J. The Redox Activity of Hemoglobins: From Physiologic Functions to Pathologic Mechanisms. Antioxid. Redox Signal. 2010, 13 (7), 1087-1123.

(57) Burkert, S.; Bittrich, E.; Kuntzsch, M.; Müller, M.; Eichhorn, K.-J.; Bellmann, C.; Uhlmann, P.; Stamm, M. Protein Resistance of PNIPAAm Brushes: Application to Switchable Protein Adsorption. Langmuir 2010, 26 (3), 1786-1795.

(58) Yin, Z.; Zhang, J.; Jiang, L.-P.; Zhu, J.-J. Thermosensitive Behavior of Poly( N Isopropylacrylamide) and Release of Incorporated Hemoglobin. J. Phys. Chem. C 2009, 113 (36), 16104-16109.

(59) Halperin, A.; Kröger, M. Collapse of Thermoresponsive Brushes and the Tuning of Protein Adsorption. Macromolecules 2011, 44 (17), 6986-7005.

(60) Jordan, R.; Ulman, A.; Kang, J. F.; Rafailovich, M. H.; Sokolov, J. Surface-Initiated Anionic Polymerization of Styrene by Means of Self-Assembled Monolayers. J. Am. Chem. Soc. 1999, 121 (5), 1016-1022.

(61) Kristinsson, H. G.; Hultin, H. O. The Effect of Acid and Alkali Unfolding and Subsequent Refolding on the pro-Oxidative Activity of Trout Hemoglobin. J. Agric. Food Chem. 2004, 52 (17), 5482-5490.

(62) Boys, B. L.; Kuprowski, M. C.; Konermann, L. Symmetric Behavior of Hemoglobin $\alpha-$ and $\beta$ - Subunits during Acid-Induced Denaturation Observed by Electrospray Mass Spectrometry $\uparrow$. Biochemistry 2007, 46 (37), 10675-10684.

(63) Griffith, W. P.; Kaltashov, I. A. Highly Asymmetric Interactions between Globin Chains during Hemoglobin Assembly Revealed by Electrospray Ionization Mass Spectrometry $\uparrow$. Biochemistry 2003, 42 (33), 10024-10033. 
(64) Kristinsson, H. G. Acid-Induced Unfolding of Flounder Hemoglobin: Evidence for a Molten Globular State with Enhanced pro-Oxidative Activity. J. Agric. Food Chem. 2002, 50 (26), 7669-7676.

(65) Sage, J. T.; Morikis, D.; Champion, P. M. Spectroscopic Studies of Myoglobin at Low pH: Heme Structure and Ligation. Biochemistry 1991, 30 (5), 1227-1237.

(66) Tomoda, A.; Takeshita, M.; Yoneyama, Y. Characterization Methemoglobin of Intermediate Hemoglobin Reduction by Ascorbic Acid * Produced during by Ascorbic Acid. J. Biol. Chem. 1978, 253 (20), 7415-7419.

(67) Zhao, X.; Mai, Z.; Dai, Z.; Zou, X. Electrochemically Monitoring the Acid and Acidic Urea-Induced Unfolding of Hemoglobin and Its Electrocatalytic Ability. Electroanalysis 2010, 22 (19), 2277-2283. 
For Table of Contents only:

\section{Controlling Enzymatic Polymerization from Surfaces with Switchable Bioaffinity}

Mohammad Divandari, Jonas Pollard, Ella Dehghani, Nico Bruns, Edmondo M. Benetti,
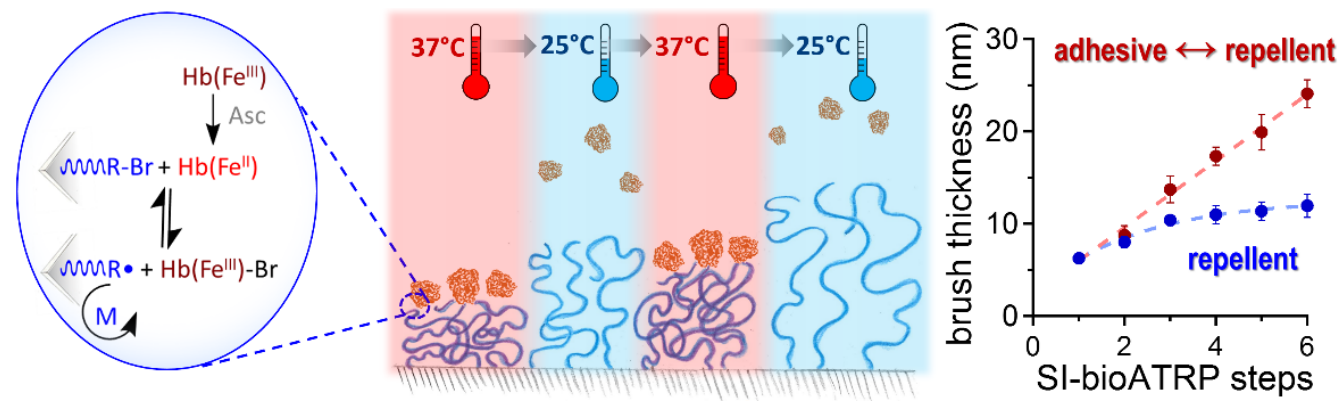